\title{
PATIOCULARIDADES: UM EXAME DA RELAÇÃO ENTRE HISTÓRIA E NARRATIVA AUDIOVISUAL A PARTIR DE SUA DIMENSÃO PRÁTICA
}

Cristiano Alencar Arrais ${ }^{1}$, Júlio César Apolinário Maia², André Luiz Melo ${ }^{3}$, DANiel Andrulis Lima ${ }^{4}$

\begin{abstract}
Resumo: O artigo aborda o processo de produção do documentário "Patiocularidades" a partir das reflexões sobre narrativa audiovisual. Problematiza o processo de expansão do conceito de narrativa dentro da historiografia e sua relação com distintos processos de narrativização da experiência, em especial aquelas associadas ao tema da temporalidade. Ao tomar como campo de teste os diferentes modos como o Pátio das Humanidades da Universidade Federal de Goiás é representado por seus frequentadores, posiciona-se em favor da incorporação das narrativas audiovisuais como uma importante área de atuação dos historiadores hodiernamente, quando é crescente o interesse pelo passado. Defende também que o domínio do manejo instrumental dos processos de narrativização e ficcionalização, aliado à dimensão autorreflexiva própria da formação do historiador, possibilita ao mesmo contribuir com o debate sobre os usos públicos da história.
\end{abstract}

Palavra-chave: narrativa audiovisual, documentarismo, historiografia

PATIOCULARIDADES: AN ANALISIS OF THE RELATIONSHIP BETWE-

EN HISTORY AND AUDIOVISUAL NARRATIVE FROM ITS PRACTI-

CAL DIMENSION

\footnotetext{
1 FH/UFG - cpaarrais@gmail.com

2 Graduado FEFD/UFG

3 Graduando FH/UFG

4 Graduando FH/UFG
} 


\begin{abstract}
The article approaches the process of production of the documentary "Patiocularidades" from the reflections on audiovisual narrative. It problematizes the process of expansion of the concept of narrative within historiography and its relationship with distinct processes of narrativization of experience, especially those associated with the theme of temporality. By taking as "experimental design" the different ways in which the Pátio das Humanidades of the Federal University of Goiás is represented by its goers, it positions itself in favor of the incorporation of audiovisual narratives as an important professional area of historians today, when the interest is increasing by the past. He also argues that the ability of instrumental management of processes of narrativization and fictionalization, combined with the self-reflexive dimension of the historian's formation, enables the historian to contribute to the debate about the public uses of history.
\end{abstract}

Key-words: audiovisual narrative, documentarism, historiography

PATIOCULARIDADES: UN EXAMEN DE LA RELACIÓN ENTRE

\title{
HISTORIA Y NARRATIVA AUDIOVISUAL DESDE SU DIMENSIÓN PRÁTICA
}

Resumen: El artículo aborda el proceso de producción del documental "Patiocularidades" a partir de las reflexiones sobre narrativa audiovisual. Problematiza el proceso de expansión del concepto de narrativa dentro de la historiografía y su relación con distintos procesos de narrativización de la experiencia, en especial aquellas asociadas al tema de la temporalidad. Al tomar como "campo de prueba" los diferentes modos como el Patio de las Humanidades de la Universidad Federal de Goiás es representado por sus frecuentadores, se posiciona en favor de la incorporación de las narrativas audiovisuales como una importante área de actuación de los historiadores de hoy, cuando es creciente el interés por el pasado. Defiende también que el dominio del manejo instrumental de los procesos de narrativización y ficcionalización, aliados a la dimensión autorreflexiva propia de la formación del historiador, posibilita al mismo contribuir con el debate sobre los usos públicos de la historia.

Palabras clave: narrativa audiovisual, documentalismo, historiografia

\section{INTRODUÇÃO: A HISTÓRIA NARRA?}

Há até pouco tempo, para a cidadela dos historiadores, o ato de narrar era entendido como uma necessidade que infelizmente, estava associada à produção do conhecimento histórico. Mesmo sendo inerente à sua criação 
enquanto gênero narrativo, distinto do mito e da tragédia (HARTOG, 1998), a narrativização dos eventos foi considerada como o calcanhar de Aquiles dos historiadores, expressão máxima de sua subjetividade. A superação desse tipo de perspectiva, realizada em virtude do diálogo com a filosofia e a antropologia, permitiu aos historiadores refletir sobre o ato de narrar, agora entendido como uma realização linguística "que tem por finalidade comunicar a um ou mais interlocutores uma série de acontecimentos, de modo a fazê-lo(s) tomar parte no conhecimento deles, alargando assim o seu contexto pragmático" (SEGRE, 1989, p.59).

Esse redirecionamento do estatuto narrativo da historiografia vem sendo defendido em tempos recentes como parte de um amplo processo de autorreflexão acerca do estatuto ontológico e epistemológico da disciplina história. Em sua crítica ao conceito de objetividade nas ciências históricas, Rüsen (1996, p. 89) sustenta que "Narratividade é um conceito que explica a relação constitutiva do pensamento histórico para com as práticas culturais da memória e identidade coletivas. Ele mostra que a cognição histórica opera sua constituição específica na vida prática mediante sua forma narrativa”. Na medida em que a narrativa não faz oposição à ideia de objetividade, a historiografia deve incorporar ao conceito de interpretação do passado, de modo inclusivo, a relação que se estabelece entre os fatos e seus procedimentos de constituição de sentido para além dos fatos. Isto é, a maneira que o historiador utiliza para contar uma história (tell a story).

Também David Carr chega a conclusão similar. É preciso distinguir entre relatos ficcionais e não-ficcionais, superando a noção ultrapassada de associação desses termos às noções de verdade e falsidade e em apoio à ideia de imaginação compartilhada entre autor e público leitor, próprio de relatos ficcionais. Além disso, em ambos os tipos de narrativas, "a imaginação, em combinação com outras capacidades, é organizada a serviço de produzir afirmações, teorias, previsões e, em alguns casos, narrativas, sobre como o mundo realmente é, ou será, ou era; e no outro caso é usado para produzir histórias sobre personagens, eventos, ações e até mesmo mundos que nunca existiram" (2004, p. 255). Não é, portanto, o uso de elementos de ficcionalidade que torna uma narrativa mais ou menos confiável, que a torna verdadeira ou falsa: "longe de se colocar no caminho da verdade histórica, esses são meios apropriados para alcançá-lo", na medida em que as narrativas históricas e ficcionais 
partilham da mesma estrutura de sentido a que denominamos realidade (ARRAIS e VALLE, 2019).

No que se refere à relação entre os historiadores e as narrativas audiovisuais, ela não está restrita à busca pela verdade factual desse tipo de produção ou pelo seu oposto, pela ênfase no caráter puramente representacional de uma narrativa audiovisual. Certamente, a pioneira reflexão de Marc Ferro (1976) não pode ser desprezada para os estudiosos dessa temática. Sobretudo pela influência na construção de abordagens distintas, como a apresentada por Henn Fabris (2008), que sistematizou o modo relativamente usual com que os historiadores tratam as narrativas audiovisuais, sobretudo no campo do ensino de história: a seleção de uma filmografia de análise e complementar, a produção de fichas técnicas, tabela de linguagem cinematográfica, os critérios de seleção, uma tabela de levantamento das representações, uma ficha de decupagem e outra de articulação fílmica.

Porém, embora essa abordagem tenha méritos inegáveis, ela enfatiza a posição do historiador como comentador, como um analista do produto final (o filme, o documentário etc.). Nessa condição o historiador é geralmente incapaz de intervir no processo produtivo e, portanto, na relação entre o público e o evento narrativo. Esse tipo de posicionamento é constantemente reproduzido em trabalhos acadêmicos que objetivam analisar filmes (CAPELATO, MORETTIN, e NAPOLITANO, 2011).

Esse tipo de perspectiva indica, segundo nossa opinião o desconforto com que os historiadores sentem-se em contribuir de forma efetiva na produção de narrativas audiovisuais. Um desconforto crescente, na medida em que observa-se um crescente volume de produções que encontram na história o pano de fundo ou mesmo um conjunto farto de experiências roteirizáveis, avançando sobre aquilo que poderíamos definir como competências eminentemente historiográficas 5 . O mau humor com o qual Darnton declinou o convite para

5 Uma listagem mínima, sem qualquer critério qualitativo, indica essa crescente demanda pelo passado: desde O Nascimento de uma nação, de D. W. Griffit (1915), O encouraçado Potemkin, de S. Eiseinstein (1925), A guerra do fogo, de Annuad (1982), até produções mais recentes, como A lista de Schindler, de Spilberg (1993), Gladiador, de Ridley Scott (2000), Argo, de BenAfleck, (2012) e Clube de compras de Dalas, de Jean-Marc Vallée(2013) e Legalize Já!, de Gustavo Bonafé (2018). Nessa lista poderiam ser acrescidas também, documentários, como Cabra marcado para morrer, de Eduardo Coutinho (1984) séries televisivas, como Roma, da HBO/BBC (2005), Dawnton Abbey, da CarnivalFilms (2010) e novelas, como Liberdade, liberdade, da Rede Globo (2016). A história é, nesse sentido, um campo fértil para os roteiristas. 
revisar um roteiro de televisão sobre a Revolução Francesa expressa bem esse tom: "A história pode ser piorada em vez de melhorada, e a pior versão de todas, pelo menos para uma nação de telespectadores, talvez seja a história como dramatização" (DARNTON, 2010, p. 75). Esse desconforto é revelador do descompasso entre os dois campos, conforme identificado por Rosenstone (2010, p. 62): "está na hora de parar de esperar que os filmes façam o que (na nossa imaginação) os livros fazem". Certamente, existem exceções e o trabalho de Natalie Zamon Davis na equipe de produção de Le retourde Martin Guerre (1982) e a equipe de pesquisa histórica que atua junto às minisséries e novelas da Rede Globo de Televisão são prova disso.

Nesse texto, defendemos a hipótese de que é possível entender o historiador também como um produtor, como alguém capaz de registrar a experiência e mesmo em face de sua condição profissional, dominar o manejo instrumental dos processos de narrativização e ficcionalização, próprios dessa linguagem. Procuramos refletir sobre essa difícil aproximação entre historiadores e narrativas audiovisuais por meio do duplo posicionamento anteriormente expresso: como produtores desde narrativas audiovisuais e como seus analistas. Utilizamo-nos para isso de uma experiência de construção de documentário, realizada no ano de 2018, intitulado "Patiocularidades" (ARRAIS et al., 2018), com o intuito de registrar as distintas formas de percepção de uma comunidade (os frequentadores do Pátio Humanidades da Universidade Federal de Goiás) sobre seu principal espaço de convivência. Após a descrição do processo que levou produção do material audiovisual, empreenderemos a análise do significado do Pátio Humanidades para os entrevistados enfatizando a relação que as distintas gerações de agentes (ex-alunos, professores e alunos atuais) construíram com o espaço.

\section{CONTRA A ORTODOXIA METODOLÓGICA}

O pontapé inicial para a construção do documentário sobre o Pátio das humanidades advém inicialmente, de um questionamento intuitivo que partiu de uma pergunta simples: "O que é o Pátio das Humanidades UFG?". O propósito desta pergunta inicial foi motivada pela necessidade de examinar mais profundamente fenômenos sociais que nos são apresentados cotidianamente, sem que estejamos atentos a eles. O Pátio das Humanidades nos forneceu um excelente cenário a partir do qual nós poderíamos lançar mão de um olhar 
mais apurado às distintas formas de organização do espaço. Dessa observação inicial, aprendemos que mais do que um espaço, estávamos lidando com um lugar - habitado, partilhado, disputado e construído historicamente, composto por camadas distintas de significados e experiências que dificilmente poderíamos traduzir em palavras. O Pátio ganhou três espectadores neste momento, que minuciosamente tentavam se aproximar de boa parcela dos elementos constituintes daquela realidade.

O debate foi fomentado pela análise feita por Cliford Geertz acerca da briga de galos balinesa. Nesse sentido, três lições foram incorporadas ao projeto que se delineava dentro de sala de aula:

a. A necessidade de imersão cultural: Conforme a descrição de Geertz, a aldeia parecia não se importar para a existência de ambos, que eram vistos como uma enorme indiferença aos olhos dos balineses. A chegada do policiamento local para reprimir a rinha de galos que acontecia na praça central da aldeia, com a presença da comunidade e dos dois antropólogos provocou, além da rápida fuga de todos os presentes, $o$ processo de reconhecimento, por parte da aldeia, da "existência" do casal Geertz: não mais eram vistos como irrelevantes, mas como socialmente aceitos, por terem preferido fugir ao invés de revelar suas identidades aos policiais.

b. A atenção às "regras do jogo": a multiplicidade comportamental do ser humano pode ser observada nas distintas e por vezes sobrepostas representações que os indivíduos constroem sobre o mundo. "Os julgamentos na corte, as guerras, as reuniões políticas, as disputas de herança e os argumentos de rua são todos comparados a brigas de galos. Até a própria ilha é percebida como tendo o contorno de um galo pequeno, orgulhoso, ereto, com o pescoço estendido, o dorso arqueado, o rabo levantado." (GEERTZ, 2008, p.189).

c. A decomposição da experiência em suas múltiplas camadas de significado: seus simbolismos conflitantes, suas incoerências culturais, seus limites interpretativos e hierarquizações não-verbais, compõem a noção de realidade: "o sistema envolvido de cortes cruzados, sobrepondo-se a grupos altamente corporativos - aldeias, grupos de parentesco, 
sociedades de irrigação, congregações de tempo, "castas" - nos quais vivem seus devotos" (GEERTZ, 2008, p. 201).

Em sequência às observações intuitivas, despretensiosas por assim dizer, e do debate realizado em sala de aula, nos propusemos a tarefa de construir um ponto de aderência dessas distintas experiências que formam o Pátio Humanidades.

A forma de uma narrativa audiovisual foi adotada por considerarmos essa uma forma mais expressiva - e porque não dizer, divertida - de captar os distintos extratos, as distintas camadas de percepções sobre o Pátio Humanidades. Conscientes de nossos déficits estilísticos, a forma escriturária, consagrada na academia e na literatura, dificilmente nos permitiria transmitir ao público leitor as cores vívidas e as expressões delicadas dos depoimentos que desejávamos coletar.

Ademais, concordamos com Lagny (2009, p. 110) de que "as narrativas audiovisuais são fontes potenciais de compreensão da consciência histórica de uma época". Nessa forma mediada de se relacionar com o mundo da vida, emergem maneiras de ver, sentir e pensar seu próprio tempo. Ademais, conforme notamos anteriormente, os processos de ficcionalização - que estão envolvidos no processo de enquadramento próprios das narrativas audiovisuais - além de não se oporem às discussões sobre o tema da referencialidade, tem um potencial mobilizador do público inegavelmente superior às outras formas narrativas. Para Rosenstone, é preciso levar em consideração que os filmes históricos são "tentativas sérias de dar sentido ao passado" (ROSENSTONE, 2010, p. 62) que não se opõem, necessariamente às formas tradicionais de representação do passado. Pelo contrário, em muitas ocasiões elas complementam a formação e por vezes tornam-se o caminho a partir do qual a cultura letrada se insere no cotidiano de jovens: "não li o livro, mas vi o filme".

Podemos ir além. As narrativas audiovisuais permitem estabelecer um outro tipo de relação com o passado, mais próxima das novas gerações, formadas em meio a uma superexposição de tipos distintos de mídias digitais. É preciso admitir que mesmo dentro da academia, a antiga relação construída entre os discentes e a bibliografia utilizada em sala de aula (artigos e livros) vem perdendo sua força. O que demonstra um preocupante descompasso entre as formas de produção de conhecimento anteriormente cultivado pelas gerações de acadêmicos estabelecidos nas universidades e os atuais processos de transmissão do 
conhecimento, capitaneados por inovações nos mecanismos de sociabilização (e-mail, Facebook, WhatsApp, Linkedin) e guarda e disseminação do conhecimento (Wikipédia, archive.org, Guttemberg Project). Emanuel Castells intitula essa nova era de informacionalismo, que tem com uma de suas principais características a velocidade com que as tecnologias da informação se implantam e se disseminam na sociedade. Para Pretto (2011, p. 107-108),

[...] essa mudança na linguagem dos jovens não tem a ver só com o teclar, e sim com todo um universo mais amplo, que inclui os RPG, a música eletrônica, o hip-hop, as conversas nos chats (batepapos), nas comunidades de relacionamento como Orkut, Facebook, Myspace, Second Life, o intenso uso que se tem dado aos microblogues como o Twitter, Identi.ca, entre tantos outros. Essa juventude é, não resta a menor dúvida, uma juventude que produz mais, que escreve mais e se manifesta publicamente. Ao assim fazer, produz novos textos em diversos contextos que nos impõe repensar os próprios processos de alfabetização. Além disso, cresce de forma vertiginosa o uso das imagens em movimento. Os sítios de publicação de vídeo, sendo o Youtube o exemplo mais visível, mas não o único, vêm mexendo radicalmente não só com o universo juvenil, mas, também, com o mundo adulto. Pesquisas indicam que cresce de forma vertiginosa a produção através dos sítios colaborativos, espaços onde todos passam a ser escritores e "jornalistas" e, por conta disso, esses blogues e microblogues com textos, sons e imagens, transformaram-se num enorme fenômeno contemporâneo.

Ora, apenas os historiadores mais ortodoxos ainda não se atentaram para os impactos dessas transformações dentro da própria profissão. O passado vem sendo sistematicamente mobilizado nas redes sociais, servindo de recurso retórico para justificar todo tipo de posicionamento político. A excessiva publicização da história tornou-se uma armadilha para o historiador, incapaz de garantir algum tipo de autoridade discursiva em meio a um conjunto infinito de discursos, cada qual reivindicando sua validade per si, sem qualquer critério de aferição.

Mas essa multiplicação de vozes sobre o passado, pode também ser tomada como uma possibilidade para os historiadores. Abordando a relação entre história e cinema, Rosenstone (2010, p. 234) lembra que na medida em que a mudança de suporte permite especular sobre a mudança na forma como refletimos sobre o passado e "se isso for verdade, talvez os nossos historiadores cineastas estejam sondando as possibilidades do futuro do nosso passado".

Com essas reflexões iniciais elaboramos um design onde os distintos extratos de experiências sobre o Pátio Humanidades pudessem convergir, 
sustentada por uma hipótese de trabalho assim sintetizada: "O Pátio das Humanidades é a expressão espacial da diversidade política e cultural da Universidade Federal de Goiás - seus conflitos, seus grupos de interesses, suas experiências individuais e coletivas, sua memória, seus impasses”. A partir dessa ideia e das observações iniciais, decidimos construir uma descrição densa desse ambiente, atentos à possibilidade de decomposição de suas partes, às regras do jogo, apenas disponíveis àqueles que partilham do mesmo campo de experiência. Em termos práticos, essa intenção foi traduzida na forma da decomposição do ambiente em diferentes camadas de percepção, associada aos distintos grupos de interesse que formam esse ambiente de socialização, obtidas por meio de entrevistas.

No processo de construção do documentário, tivemos vários momentos de reconfiguração de nossas ideias iniciais, de acordo com as discussões e "brainstorms" que realizávamos semanalmente. A princípio, obtivemos gravações dos inúmeros cenários do Pátio das Humanidades, desde cenas abertas, panorâmicas, até locações fechadas que visavam, ao mesmo tempo, construir um estoque de cenas capazes de prover o documentário, mas também aprender e brincar com o processo de construção das cenas.

Inicialmente, a filmagem se propunha a captura de imagens abertas que apanhassem acontecimentos e expressões da rotina e do dia-a-dia do Pátio. Para tanto as cenas eram produzidas em diferentes horários, a partir de vários ângulos e com a intenção de captar a maior quantidade de acontecimentos. Muito do que inicialmente foi expresso durante a etapa de análise subjetiva pode ser evidenciado em cenas e imagens coletadas durante três semanas de filmagens. No momento da filmagem não havia preocupação com seleção, montagem e articulação das cenas capturadas, mas somente o ato de despretensiosamente registrar acontecimentos: para utilizar o termo de Foucault, éramos positivistas felizes, com uma câmera na mão.

Quanto às entrevistas, as perguntas foram tanto moldadas em sala quanto no momento da entrevista em si, questões abertas destinadas a identificar, através das opiniões de vários indivíduos, as imagens recorrentes sobre o Pátio. Foram feitas várias perguntas sobre a história do pátio e sobre como eles viam as pessoas que frequentavam o ambiente. Decidimos entrevistar várias pessoas, professores "das antigas", da "nova geração", alunos "engajados" e "alienados", progressistas e conservadores, sempre considerando as referências e atribuições que os alunos produziam sobre si mesmos e sobre seus 
próprios colegas. O pátio, esse emaranhado de visões e relações, que formam uma parte importante do ambiente acadêmico, era um objeto de locação sem restrições prévias.

Nesse processo de aprendizagem, a montagem do "caminho do macaco" foi preciosa: uma gravação em linha reta pelo pátio na perspectiva de um dos macacos pregos dos arredores da faculdade, com depoimentos que inseriam os macacos como protagonistas das experiências narradas. A "linha do beijo", o "mosaico de vozes", e a montagem colaborativa de cenas com imagens e vídeos pessoais de colegas da $\mathrm{FH}$, foram outras ideias surgidas desses encontros.

Fıcura 1: Equipe realizando locações externas. Observa-se ao fundo as paredes dos prédios com os grafitis.

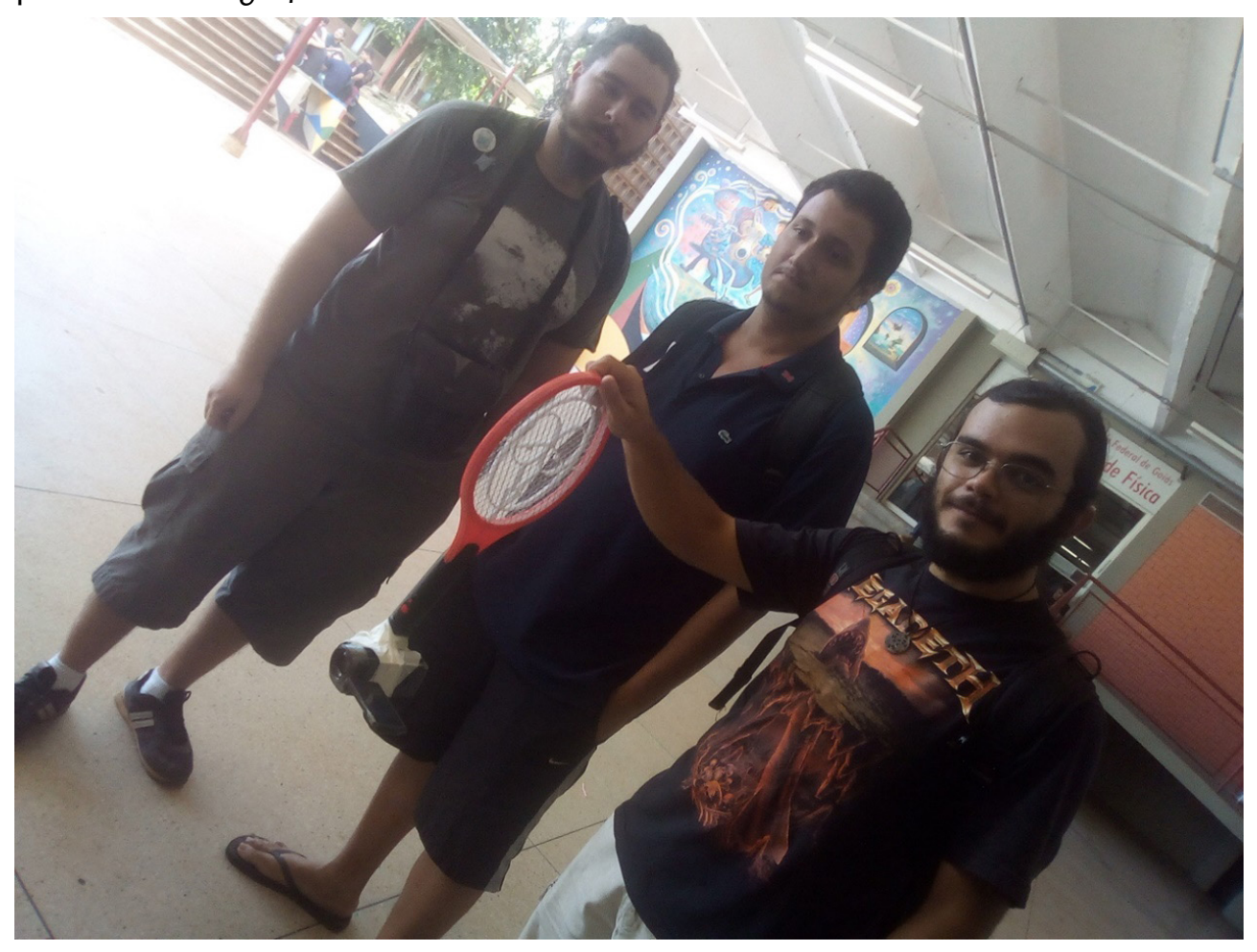

Fonte: Arquivo pessoal Cristiano Arrais. 18 de maio, 2018.

Ao final, algumas dessas ideias se mostraram impossíveis de serem executadas e o planejamento inicial acabou se moldando as nossas limitações técnicas e de tempo. As palavras de Coutinho, Xavier e Furtado. (2014, p. 175), são reveladoras da constatação a que chegamos ao final desse processo: "se filmo durante uma hora, ficam na edição final cinco ou sete minutos. Faço dela um concentrado daquilo que eu acho que é o melhor". 
Reunidas as locações, realizamos a decupagem do material coletado, catalogando cada cena e entrevista de acordo com o assunto. Os itens separados na decupagem ajudaram na confecção do trabalho final, pois foi apenas com esse processo que conseguimos perceber com clareza as diferentes facetas que o pátio tinha, de acordo com a visão dos entrevistados: tristeza, medo, ponto de encontro, lazer e discussão, como lugar político, como lugar de uma memória nostálgica ou de uma utopia social.

\section{A PERCEPÇÃO GERACIONAL: ENTRE A NOSTALGIA E A UTOPIA}

Em 2017, como estratégia para combater o tráfico de drogas que havia se estabelecido na Universidade Federal de Goiás, a reitoria da UFG e as faculdades de História, Ciências Sociais, Filosofia, Artes Visuais, Informação e Comunicação, o Instituto de Física e Centros Acadêmicos elaboraram um plano de revitalização do Pátio das Humanidades, o que resultou nas propostas de pequenas reformas no espaço físico e na elaboração de um projeto artístico-cultural para o mesmo. Além da preocupação com a segurança dos frequentadores daquele espaço, estava em discussão também o tema da reconstrução de um importante espaço de socialização dentro da universidade ${ }^{6}$.

O objetivo era estabelecer uma política de ocupação dos espaços com a promoção de exposições, debates, shows e atividades acadêmicas de extensão, inibindo o consumo de drogas local. O projeto, amplamente debatido dentro das faculdades com os discentes, seja por meio dos Centros Acadêmicos e Assembléias de estudantes, teve como aspecto mais visível a limpeza do ambiente, a instalação de painéis de grafitis e a retirada dos bancos e mesas do local.

Para João Paulo Camargo, estudante do terceiro ano de história, já é possível observar uma mudança, fundamentalmente associada ao espaço:

Eu acho que o pátio em si, o centro do pátio, é um lugar muito macabro. Onde a galera usa droga 'e tal' [...] melhorou muito em minha opinião depois que retiraram as mesinhas,

6 Com o objetivo de aumentar a segurança no local forma implementadas medidas de intervenção física no espaço, tais como a retirada das mesas e fechamento do redário, a ampliação do número de câmeras de monitoramento, o estabelecimento de um protocolo para intervenção da Política Militar dentro do Campus, além do incentivo do uso da ferramenta de denúncia constante no aplicativo Minha UFG. Destaca-se também nesse conjunto de ações, a implementação de um projeto de extensão comum às unidades acadêmicas envolvidas, integradas dentro de um projeto mais amplo, intitulado Topofilias. 
porque antes ficavam traficantes ali e eu não estou vendo mais traficantes. Não sei se eles estão [no pátio], mas eu não estou vendo, [...] não está tão visível quanto era antes (ARRAIS et al., 2018, 03'05”).

A mesma ênfase pode ser notada em outros dois depoimentos, de Thiago Silva, estudante do terceiro ano de história e José Eustáquio, discente do Programa de Pós-Graduação em História:

É um lugar de convivência. Um espaço que era para a gente dividir com pessoal da física [Curso de Graduação em Física], mas eles fecharam a porta. Quando tinham os bancos aqui, a gente ficava sentado, matava aula. [Tem] a mesma função do CA [Centro Acadêmico], só que num espaço aberto (ARRAIS et al. 2018, 11'11").

Antes de tudo ele é um lugar de convivência estudantil. Então [...] tem que ser um lugar que tem que estar tendo evento, a política tem que estar sendo discutida. [...] não adianta nada pintar o departamento, fazer grafite - eu entendo os grafites, mas e a política? Entendeu? [E] a politização do espaço? (ARRAIS et al., 2018,11'46").

A mudança, associada ao espaço foi, portanto, o aspecto mais evidente dentro das entrevistas selecionadas para compor o documentário. Essa ênfase é plenamente compreensível, na medida em que,

Em contraposição ao tempo que oferece continuamente a imagem da mudança, o espaço oferece a imagem da permanência e da estabilidade. Os lugares recebem a marca de um grupo e a presença de um grupo deixa marcas num lugar. Todas as ações do grupo podem ser traduzidas em termos espaciais e o lugar ocupado pelo grupo é uma região de todos os elementos da vida social. Ao mesmo tempo que o espaço faz lembrar uma maneira de ser comum a muitos homens, faz lembrar, também, costumes distintos, de outros tempos. Sobretudo, faz lembrar de pessoas e relações sociais ligadas a ele. Nesse sentido é, sempre, fonte de testemunhos (SCHIMIDT \& MAHFOUD, 1993, p 291).

Os depoimentos coletados formam um precioso conjunto impressões sobre a relação que os indivíduos constroem com o espaço tendo como categoria estruturante a noção de mudança - um deslocamento ou a percepção de uma diferença, entre dois momentos, provocando a sensação de distinção entre o antes e o depois. Perceber a mudança significa construir um significado social para si mesmo e para seu passado, seja através de incrementos de experiências (entendida como extensão do passado, o que leva ao fenômeno da incorporação) ou de ruptura (quando a estrutura normativa do passado é tensionada de 
tal fora que se torna incapaz de solucionar os problemas do presente) (HOBSBAWN, 1998).

No conjunto de entrevistas apresentadas no documentário, destacam-se dois modelos de interpretação da mudança, por meio da utopia e da nostalgia.

Nostalgia é uma categoria temporal que constrói uma visão idealizada sobre o passado. Em O Campo e a Cidade, Raymond Willians (2011) observou que esse tipo de agenciamento do passado produz uma espécie de endemização, sempre associada a um fundo emocional. É o que se nota no depoimento de Ulisses do Valle, ex-aluno da Faculdade de História e atualmente docente da instituição:

O pátio fisicamente era muito diferente né? Chão batido, tinha a Brioche. Mas o fato é que naquele contexto o pátio era um local de muito encontro e diversas manifestações políticas, artísticas e culturais, todas elas organizadas autonomamente pelos próprios alunos ou os centros acadêmicos ou pelo próprio DCE (ARRAIS et al., 2018, 02'09”).

O passado reconstruído por meio da memória do depoente mobiliza a reflexão do ouvinte para a distância entre o ontem e o hoje. Nesse caso, não basta identificar a mudança, é preciso qualifica-la e, em certo sentido, mitifica-la por meio de ênfase na antítese de tempos (o antes é fundamentalmente diferente do hoje) e de uma espécie de metonimificação da experiência (uma experiência pontual representada como a totalidade das experiências possíveis em uma determinada época).

Em direção semelhante, o entrevistado Luiz Sérgio, professor da Faculdade de História desde a década de 1990, distingue os impasses que são experimentados pelo novo contexto de utilização do Pátio Humanidades:

Antes era o pátio das ciências humanas. Todas as escolas estavam aqui nesse prédio. E o hoje a gente está separado. Sociologia e antropologia foram para um prédio ali embaixo, estão 'isoladassos' lá, longe dos alunos e longe da gente. [...] A gente ainda se junta aqui porque algumas aulas são ainda aqui, mas estamos dispersos hoje e isso é um grande problema. Antes era mais fácil mobilizar as humanidades porque a gente se encontrava todo dia no pátio, os professores estavam aqui no corredor, todo mundo se conhecia e isso se perdeu (ARRAIS et al., 2018, 01"6").

Em The future of nostalgia, Svetlana Boym examinou o conceito de nostalgia. Segundo a autora, nostalgia "is a longing for a home that no longer exists or has never existed. Nostalgia is a feeling of loss and displacement, but it 
is also a romance with one sown fantasy. Nostalgic Love can only survive in a long-distance relationship." (2001, p. 14). Ante as encruzilhadas do presente, a idealização do passado é um dos recursos mais utilizados, seja por indivíduos seja por grupos políticos ${ }^{7}$.

A mudança foi percebida sob outro viés pela atual geração de discentes. Nesse caso, a ausência de continuidade geracional implicou numa falta de continuidade entre os dois modelos interpretativos da mudança: para a atual geração de discentes o passado não pesa sobre seus ombros, a mudança não implica numa alteração da antiga ordem, na alteração dos padrões e modelos de sociabilidade e de intervenção no espaço.

Quando eu entrei aqui o pátio assim, ele é um, eu acho que é um espaço de interação mesmo, não só da gente aqui da faculdade. Acho muito divertido encontrar pessoas de outros institutos. Sempre foi um lugar assim, pra relaxar, de lazer mesmo. Mas ultimamente, antes da... ano passado ele tinha ficado bem 'top' principalmente aqui no noturno fica bem pesado, 'tava' meio impraticável o pátio no passado. Acho que ele voltou a ser esse ponto de lazer, de encontro dos institutos (ARRAIS et al., 2018, 12’45”).

Observa-se, portanto, que quando o dilema geracional não norteia a percepção do entrevistado, as preocupações seguem caminho distinto. Essa distinção pode ser explicada em função da distinção entre dois estratos corporativos (alunos e professores), que ocupam interesses e valores comuns às suas corporações.

7 A nostalgia não é, nesse sentido, um discurso sobre o passado, mas sobre o presente e para o presente, utilizando o passado mitificado para mobilizar um auditório. Essa estratégia pode ser notada no debate presidencial de 2018, onde um dos candidatos, numa franca atitude de deturpação historiográfica, negava os crimes políticos ocorridos por agentes do Estado brasileiro contra os opositores ao regime ditatorial implantado em 1964. Nesse nível, a nostalgia, como recurso memorialístico, serviu de fundamento emocional poderoso para o fortalecimento de perspectivas conservadoras e "restauradoras" de uma suposta ordem perdida. Nesse explícito abuso da experiência, a argumentação nostálgica acessou as camadas mais profundas do imaginário salvacionista sobre o período militar, permitindo ao candidato sair vitorioso nas eleições presidenciais, mesmo com uma pauta explicitamente retrógrada em termos de direitos civis. 
Ficura 2: Alunos realizando atividades culturais no período das ocupações, em 2016. Ao fundo, cartazes e pichações anteriores ao projeto de revitalização do espaço.

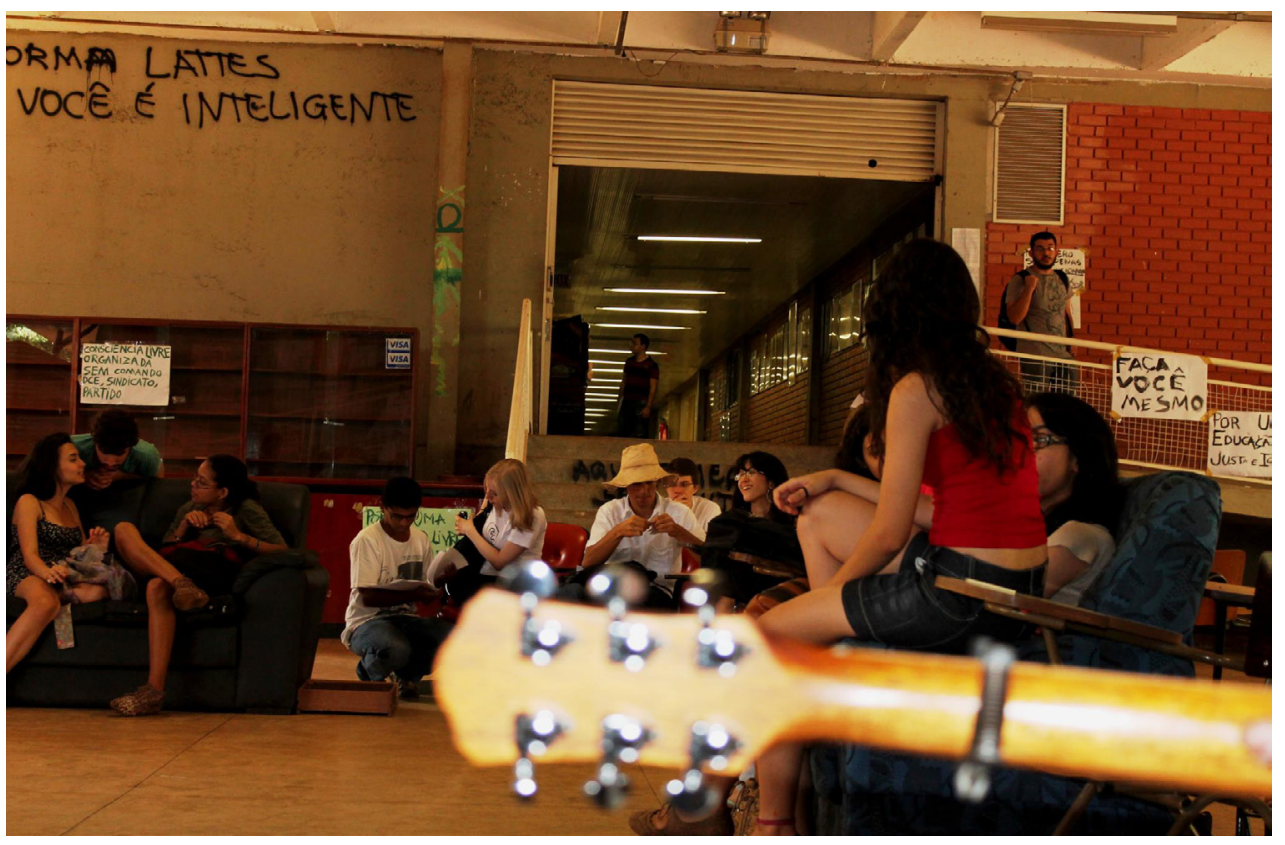

Fonte: ACERVo PESSOAl RicARdo LenARD.

A partilha de valores e interesses entre pessoas de uma mesma faixa etária, que experimentam eventos em conjunto, formam a base emocional de uma geração. Trata-se portanto, de uma similaridade de influências existentes, no limite, de uma compreensão da temporalidade partilhada, que é distinta da idade nominal dos indivíduos envolvidos. Daí a possibilidade de existência daquilo que Mannheim chama de "não contemporaneidade dos contemporâneos" (WELLER, 2010, p. 209).

Para o discente Patrick Tavares,

As ocupações foram uma excelente forma da gente de sair dessa bolha. Por que estamos dentro de uma bolha dentro da faculdade ainda - infelizmente - a universidade, ela é pública 'né? Ela pode ter acesso de qualquer pessoa, mas as pessoas lá fora não sabem disso. Então assim, abriu muito a mente, a gente é muito privilegiado de estar aqui dentro. Então não é que a gente é melhor que as outras pessoas por ter entrado na 'federal' (UFG) 'né? Na verdade é a gente é privilegiado por estar na 'federal' sabe (ARRAIS et al., 2018, 04'52").

Observa-se aqui o delineamento de um horizonte utópico para o significado de uma experiência política específica que teve no Pátio Humanidades um de seus principais focos de atuação (O movimento das Ocupações, de 2016). Para Rüsen (2007, p. 136), "um pensamento utópico define-se pela negação da 
realidade das circunstâncias dadas da vida. Ela articula carências, na expectativa de circunstâncias de vida nas quais desaparecessem as restrições à satisfação dessas carências.”. Em outras palavras, diante dos impasses apresentados pelas condições atuais do agir e sofrer humanos, propõe-se imaginar condições totalmente diversas, livres das contrições da experiência. Originalmente associada a uma perspectiva espacial, a um ambiente novo (que tem na obra de Tomas Morus sua mais conhecida elaboração), a utopia, pensada como futuro, não pode ser capturada pela experiência, já que oferece tão-somente um recurso emocional compensatório.

De toda forma, estamos a tratar de um superavit de carências que não encontra relação com o mundo a não ser como frustração ou ameaça na medida em que suas realizações são sempre parciais, provisórias e limitadas. Talvez em virtude disso é que também a distopia, entendida como utopia negativa e desesperança em níveis distintos (BENTIVÓGLIO, 2017), também pode ser encontrada entre os entrevistados:

A gente conseguiu durante as ocupações, levar mais de quinhentos alunos e apoiadores pra Brasília na PEC, na luta contra a PEC, e mostrar que existe uma força, os estudantes não estão mortos, a gente não 'tá' aqui apenas pra assistir a nossa aula e ir embora pra casa 'saca', participamos do cenário político, mesmo com esse governo temeroso aí, tentando nos anular 'né? Colocando a polícia militar aqui dentro e coisas do tipo. Então acho que as ocupações tiveram excelentes pontos positivos (ARRAIS et al., 2018, 10'56”).

Diante da possibilidade de um futuro distópico, um dos entrevistados, o discente Dyeenmes Carvalho, demonstrou preocupação:

[...] nós temos um grupo notoriamente feminista, você tem o pessoal [...] da linha anárquica ou comunista. [...] Eu particularmente desconheço quem são os 'coxinhas', [...] fascistas ou se tem outros [...], talvez possa existir. Eu vejo que tem uma galera que não se encaixa em nenhum desses grupos, não se define por essas categorias de 'sou feminista', 'anárquico' ou 'comunista'. Tem um pessoal que acho que não se identifica com nenhum desses e de alguma maneira se encontrou (ARRAIS et al., 2018, 07’35”).

Eu acho que a gente tem questões de afinidade, tem aqueles com os quais nós nos identificamos independente da linha em que pertença. Mas o que está me preocupando na FH é que tem se formado grupos muito rígidos, muito enrijecidos, e você não consegue entrar nesses grupos. [...] Pessoas que se alinham a outros alunos e formam unidades [...] como se fosse um bloco monolítico. Eu acho isso ruim para $\mathrm{FH}$, porque a proposta de Universidade, de universo, é justamente o espaço em que essas relações são mais fluidas. 
E essa formação de grupos, que são muito rígidos e que têm um discurso enfático de uma linha, [...] tende a fazer com que a FH possa ser aparelhada para discutir outra ideia. Eu acho que essa não é a proposta. A proposta é o seguinte: eu posso pertencer a um grupo, mas eu converso com todo mundo porque é isso que eu 'tô' fazendo aqui. Eu quero saber o que o 'coxinha' pensa, o que ele é, o porquê ele é, o porquê a 'feminista' hoje defende isso, porque o pessoal 'anarquista' está interessado nessa determinada matéria. Então eu posso não ser anarquista, [...] posso não ser comunista, mas eu não posso retirar dessa pessoa o espaço de discursividade de opinião que ela tem. Acho que a FH tem que ensejar isso, se não é isso que a gente tá fazendo, eu acho que o prejuízo enquanto instituição, enquanto Universidade pro nosso país é muito grande (ARRAIS et al., 2018, 09’04”).

Preocupação pode ser definida como um tipo de mobilização específica do horizonte de expectativa que se caracteriza pelo temor na possibilidade de perturbação da ordem (geralmente de teor moral). A preocupação projeta a noção de crise, antecipando-a no presente e é motivada por um senso de responsabilidade do agente em relação ao agora.

Temos na preocupação o ponto de encontro entre as gerações. Ela está presente entre os dois grupos aqui identificados, indicando uma partilha geracional. Essa partilha, esse lugar comum onde distintas memórias e expectativas podem ser interpoladas e articuladas está associado ao espaço construído pelas sucessivas gerações de professores e alunos, num sentido mais amplo: lugar de convivência, de interação, de distintas manifestações políticas, artísticas e culturais, onde "todo mundo se conhecia", de resistência às contrições externas, de convivência entre agrupamentos distintos, de partilha de distintas discursividades. Esses são os termos atribuídos pelos seus próprios entrevistados. Esse agregado de percepções, reunidos na forma de preocupação, certamente, não é condição suficiente para a ação, mas funciona como o substrato necessário para o agir.

O Pátio Humanidades é, nesse sentido, a expressão mais concreta de uma partilha de valores que tem na ideia de universidade o seu ponto de encontro: um espaço onde se cultiva o saber humano em toda a sua diversidade, onde o termo respeito é sempre associado à noção de crítica e onde a noção de autoridade é atribuída àqueles que cultivam a autonomia do pensamento. É, o local onde o conceito de liberdade é quotidianamente colocado em teste com o objetivo de melhor defende-lo. Esse talvez seja o significado último do Pátio Humanidades da Universidade Federal de Goiás. 


\section{Considerações Finais}

Do processo de produção do documentário e da reflexão em torno dessa experiência, consideramos importante enunciar algumas questões inerentes à experiência de produção do documentário.

Primeiro, esse documentário não é história acadêmica, embora tivesse potencial para sê-lo, se assim desejassem seus produtores. A diferença de suporte é apenas mais um dos complicadores a serem adicionados à prática historiográfica, mas não um impeditivo. Admite-se que o critério de seletividade atuou no processo de produção do documentário em diversos momentos com o objetivo de garantir a harmonia discursiva entre depoentes, imagens coletadas e a proposta inicial do documentário. $\mathrm{O}$ resultado foi sim, uma amostra seletiva, particular, mas intersubjetivamente controlada sobre a forma como o espaço habitado é construído e incorporado ao campo de experiência de uma comunidade. $\mathrm{O}$ corte geracional enfatizado nesse artigo comprova essa argumentação na medida em que distintos extratos geracionais construíram visões distintas sobre o mesmo espaço.

Em segundo lugar, a distinção entre as duas formas de narrativa não passa pelas noções de referencialidade, ficcionalidade, verdade ou falsidade. Esse tipo de distinção, que ainda flerta com o realismo epistemológico do século XIX, não consegue incorporar as profundas modificações a que a historiografia vem sendo submetida nas últimas décadas.

A discussão sobre o estatuto da imagem e sobretudo, sobre o conceito de representação, proveniente do pós-modernismo torna-se, nesse sentido, estrutural para a abordagem da questão na medida em que as estratégias estéticas de organização de imagens e discursos são diretamente relacionadas aos procedimentos imaginativos dos responsáveis pela produção de uma narrativa audiovisual. Infelizmente, essa relação causa, ainda hoje, pouca preocupação entre os historiadores. Salvo raras exceções, os habitantes da cidadela são incapazes de transitar entre o terreno árido das discussões que envolvem a historiografia pós-moderna e a dimensão prática do pensamento por imagens e da estrutura colaborativa, próprias das narrativas audiovisuais. 


\section{REFERÊNCIAS BIBLIOGRÁfICAS}

ARRAIS, Cristiano; MELO, André Luíz; LIMA, Daniel Andrulis; MAIA, Júlio César Apolinário. Pátiocularidades. Documentário. Universidade Federal de Goiás (UFG). Faculdade de História. 2018. Disponível em: <https://www.historia.ufg.br/n/107802-patiocularidades-documentario-produzido-por-alunos-da-disciplina-ideias-saberes-e-escritas-da-e-na-historia-2018-1>. Acesso em 26 set. 2018.

ARRAIS, Cristiano Alencar; VALLE, Ulisses. David Carr. In: BENTIVÓGLIO, Julio. AVELAR, Alexandre Sá (Org.). Os desafios da história no século XXI. Petrópolis: Vozes, 2019 (No Prelo).

BENTIVÓGLIO, Julio Cesar. História \& distopia. Vitória: Editora Milfontes, 2017.

BOYM, Svetlana. The future of nostalgia. New York: Basic Books, 2001.

CAPELATO, Maria Helena; MORETTIN, Eduardo; NAPOLITANO, Marcos; SALIBA, Elias Thomé (Orgs.). História e cinema: dimensões históricas do audiovisual. São Paulo: Alameda, 2011.

CARR, David. History, fiction, and human time: historical imagination and historical resposibility. In: ; FLYNN, Thomas; MAKKREEL, Rudolf. (Orgs.). The Ethics of History. Evanston: Northwestern University Press, 2004.

COUTINHO, Eduardo; XAVIER, Ismail; FURTADO, Jorge. "O sujeito (extra) ordinário". In: MOURÃO, Maria Dora; LABAKI, Amir (Orgs.). O cinema do real. São Paulo: Cosac Naify, 2014.

DARNTON, Robert. O beijo de Lamourette: mídia, cultura e revolução. São Paulo: Companhia das Letras, 2010.

FERRO, Marc. O filme: uma contra-análise da sociedade? In: LE GOFF, Jacques; NORA, Pierre (Orgs.). História: novos objetos. Rio de Janeiro: F. Alves, 1976.

GEERTZ, Clifford. Um jogo absorvente: notas sobre a briga de galos balinesa. In:

A interpretação das culturas. Rio de Janeiro: LTC, 2008.

HARTOG, François. A Arte da Narrativa Histórica. In: BOUTIER, Jean; JULIA, Dominique (Orgs.). Passados Recompostos: campos e canteiros da História. Rio de Janeiro: Editora UFRJ: Editora FGV, 1998.

HENN FABRIS, Elí. Cinema e educação: um caminho metodológico. Educação \& Realidade, n. 33, 2008.

HOBSBAWN, Eric. Sobre a história. São Paulo: Companhia das Letras, 1998.

LAGNY, Michèle. O cinema como fonte de história. In: NÓVOA, Jorge; FRESSATO, Soleni Biscouto; FEIGELSON, Kristian (Orgs.). Cinematógrafo: um olhar sobre a história. São Paulo: Editora Unesp, 2009.

PRETTO, Nelson de Luca. O desafio de educar na era digitaleducações. Rev. Port. de Educação, v.24, n. 1, p. 95-118, 2011. 
ROSENSTONE, Robert. A história nos filmes, os filmes na história. São Paulo: Paz e Terra, 2010.

RÜSEN, Jörn. Narratividade e objetividade nas ciências históricas. Textos de história, vol. 4, n. 1, 1996.

História viva. Brasília: Editora UnB, 2007.

SCHMIDT, Maria Luisa Sandoval; MAHFOUD, Miguel. Halbwachs: memória coletiva e experiência. Psicologia USP, v.4, n.1-2, p.285-298, 1993.

SEGRE, Cesare. Narração/Narratividade. In: Enciclopédia Einaudi. v. 17. Literatura-Texto. Lisboa: INCM, 1989.

WELLER, Wivian. A atualidade do conceito de gerações de Karl Mannheim. Sociedade e Estado, v.25, n.2, p.205-224, 2010.

WILLIANS, Raymond. O campo e a cidade. São Paulo: Companhia das Letras, 2011.

Recebido em dezembro de 2018.

Aprovado em dezembro de 2018. 